Communication

\title{
Development of a Novel Catalytic Membrane Reactor for Heterogeneous Catalysis in Supercritical $\mathrm{CO}_{2}$
}

\author{
Nazrul M. Islam ${ }^{1,2}$, Maya Chatterjee ${ }^{1}$, Yutaka Ikushima ${ }^{1}$, Toshiro Yokoyama ${ }^{1}$ and \\ Hajime Kawanami ${ }^{1, *}$ \\ 1 Research Center for Co MPact Chemical Process, National Institute of Advanced Industrial Science \\ and Technology (AIST), 4-2-1 Nigatake, Miyagino-Ku, Sendai, 983-8551, Japan; \\ E-Mails: islam.n.ab@m.titech.ac.jp (N.M.I.); c-maya@aist.go.jp (M.C.); \\ y-ikushima@aist.go.jp (Y.I.) \\ 2 Department of Organic and Polymeric Materials, Tokyo Institute of Technology, 2-12-1-S5-20, \\ Ookayama, Meguro-ku, Tokyo 152-8552, Japan \\ * Author to whom correspondence should be addressed; E-Mail: h-kawanami@aist.go.jp; \\ Tel.: +81-22-237-5214; Fax: +81-22-237-5214.
}

Received: 16 December 2009; in revised form: 5 January 2010 / Accepted: 6 January 2010 /

Published: 13 January 2010

\begin{abstract}
A novel type of high-pressure membrane reactor has been developed for hydrogenation in supercritical carbon dioxide $\left(\mathrm{scCO}_{2}\right)$. The main objectives of the design of the reactor are the separate feeding of hydrogen and substrate in $\mathrm{scCO}_{2}$ for safe reactions in a continuous flow process, and to reduce the reaction time. By using this new reactor, hydrogenation of cinnamaldehyde into hydrocinnamaldehyde has been successfully carried out with $100 \%$ selectivity at $50{ }^{\circ} \mathrm{C}$ in $10 \mathrm{MPa}\left(\mathrm{H}_{2}: 1 \mathrm{MPa}, \mathrm{CO}_{2}: 9 \mathrm{MPa}\right)$ with a flow rate of substrate ranging from 0.05 to $1.0 \mathrm{~mL} / \mathrm{min}$.
\end{abstract}

Keywords: catalytic membrane reactor; supercritical carbon dioxide; mesoporous silica membrane; selective hydrogenation; cinnamaldehyde

\section{Introduction}

Supercritical carbon dioxide $\left(\mathrm{scCO}_{2}\right)$ is an environmentally benign reaction medium because of its unique properties compared to conventional organic solvents, such as high diffusivity, low viscosity 
and high miscibility with gases, such as $\mathrm{H}_{2}, \mathrm{O}_{2}$ etc. These physical properties can be easily tuned by adjusting the pressure and temperature, and various reactions have been accelerated with high yields and selectivities [1]. Despite the many advantages of homogenous catalytic reactions in $\mathrm{scCO}_{2}$, the difficulties of the product-catalyst separations still remain.

To overcome these difficulties, a flow reaction system in the presence of heterogeneous catalyst in $\mathrm{scCO}_{2}$ has been developed [2], and an inorganic membrane $\mathrm{scCO}_{2}$ reactor has been reported [3-6]. Membrane reactors are multifunctional reactors with compact design and are currently being applied to various chemical reactions in both the academic and industrial fields [7]. The membranes used have structures with small pores and are thus known as nanofiltration membranes. They allow the easy separation of organic molecules and catalyst by passing through the small pores. Generally, organic membranes are used for various organic syntheses. However, these membranes face several shortcomings, like swelling, lack of stability and unsuitability for high pressure conditions. On the other hand, various types of inorganic membrane have been developed, some of which are also available for high pressure conditions [8-10]. Inorganic membranes exhibit physical and chemical properties are comparable or better than those of organic membranes, including a better structural stability and no problems of swelling or compaction. Moreover, a silica membrane showed high $\mathrm{H}_{2}$ permeance over $\mathrm{CO}_{2}$ [11]. This approach has been successfully applied to a system in $\mathrm{scCO}_{2}$ medium in the presence of homogeneous catalysis. However, those methods still have some disadvantages like low solubility of homogeneous catalysts in $\mathrm{scCO}_{2}$ and to increase the solubility, expensive ligands such as perfluoroalkyl (low cohesive energy density) are necessary [12].

Here, we have developed a new membrane reactor containing a mesoporous silica membrane (inorganic membrane) supported on $\alpha$-alumina with a heterogeneous catalyst in $\mathrm{scCO}_{2}$ and demonstrated the hydrogenation of cinnamaldehyde (CAL) into hydrocinnamaldehyde (HCAL) or hydrocinnamylalcohol (HCOL). The objective of the present method was to develop a membrane reactor that can be used for reactions in $\mathrm{scCO}_{2}$ to achieve good selectivity of the desired products.

\section{Experimental Section}

\subsection{Materials}

All the chemicals used in this study were of reagent grade. P123 copolymer was received as a sample complements of BASF, cetyltrimethylammonium bromide (CTABr), $\mathrm{PdCl}_{2}$ and trans-cinnamaldehyde (99\%) were obtained from Aldrich. Tetraethylorthosilicate (TEOS, 95\%), $\mathrm{HCl}$, and $\mathrm{NaOH}$ were from Wako Pure Chemicals Co. Ltd. Hydrogen (99.99\%) and carbon dioxide (>99.99\%) were supplied by Nippon Sanso. Co. Ltd.

\subsection{Construction of a Catalytic Membrane Flow Reactor}

\subsubsection{Schematic diagram of the reactor}

Figure 1 shows the schematic flow model of the novel catalytic membrane flow reactor (CMFR). The cylindrical reaction unit of the CMFR is placed in a constant temperature water bath to maintain the reaction temperature. A detailed description of the reactor unit is given described in the following 
section. Hydrogen gas is introduced into the syringe pump SP1 (ISCO DX260), then $\mathrm{CO}_{2}$ added into the syringe pump SP1 up to the desired pressure by JUSCO $880 \mathrm{PU} \mathrm{CO}_{2}$ delivery pump P1. Syngas $\left(\mathrm{H}_{2}+\mathrm{CO}_{2}\right)$ was delivered into the inner tube of the membrane reactor (AB in Figure $2 \mathrm{a}$ ) from In 1. The substrate stream from high pressure pump P2 was mixed at $\mathrm{T} 2$ with $\mathrm{scCO}_{2}$ delivered by $\mathrm{P} 3$ (JUSCO $\mathrm{CO}_{2}$ delivery pump), then introduced into the membrane reactor through In 1 . Pressure gauges PG1 and PG2 are used to monitor the exact pressure of the reaction unit. Total pressure was controlled by a JUSCO Back Pressure Regulator (BPR). Finally, the product was collected in the trap which is cooled at $0{ }^{\circ} \mathrm{C}$ by ice. Product yields were obtained by GC analysis (Varian CP-3800) with tridecane as a standard, and the identities of all products were confirmed by GC-MS (Varian CP-3800-1200L), using authentic samples for comparison.

Figure 1. Schematic diagram of the catalytic membrane reactor. SP1: Syringe pump; P1: $\mathrm{CO}_{2}$ delivery pump; P2: Reciprocating liquid pump; P3: $\mathrm{CO}_{2}$ delivery pump; T1 \& T2: T-shape mixer, Reactor: High-pressure membrane reactor, In 1: Inlet of outer tube of Reactor; In 2: Inlet of inner tube of Reactor, Out 1: Outlet of out tube of Reactor; Out 2: Outlet of inner tube of Reactor; R2: Reaction Chamber, R3: Outlet compartment of the reaction chamber; PG1: Pressure Gauge for outer tube of Reactor, PG2: Pressure Gauge for inner tube of Reactor; BPR: Back Pressure Regulator.

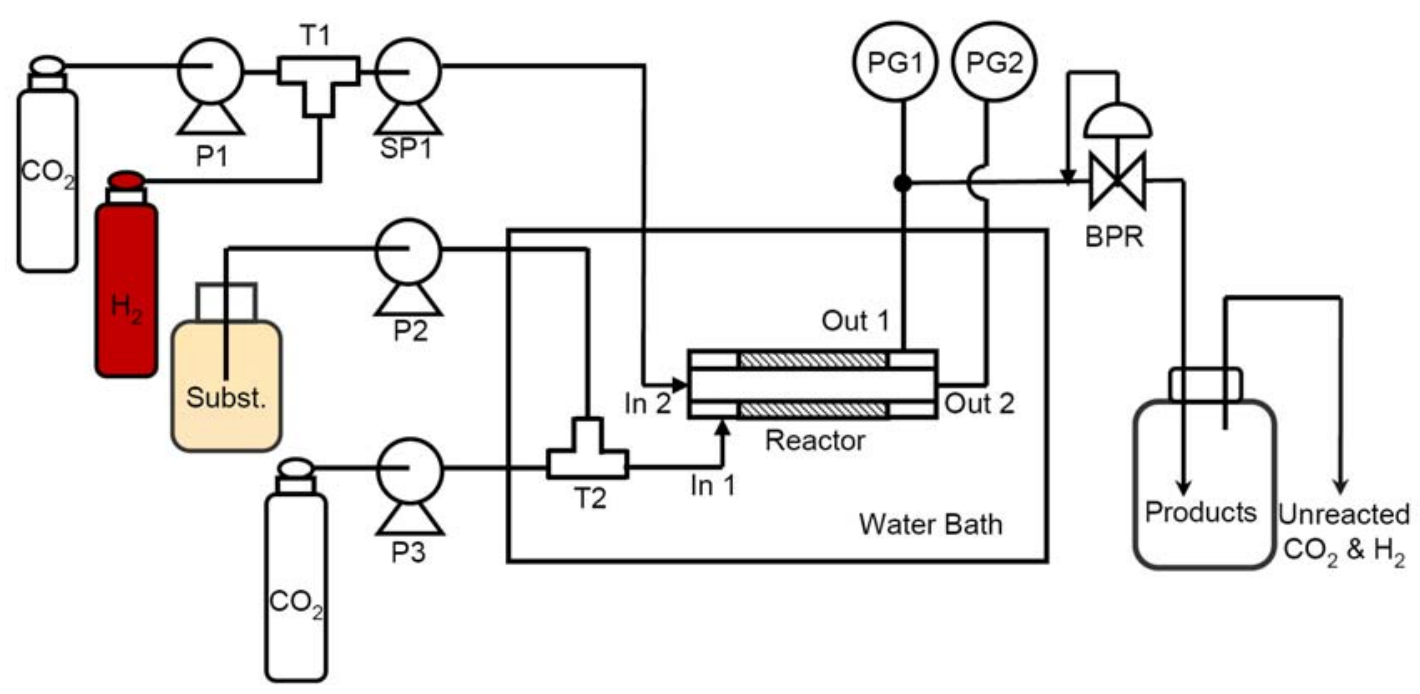

When the reaction was started, the inside and outside pressures of membrane reactor should be maintained almost equally, then the pressures should be increased gradually and carefully. Because membrane reactor is easily broken, and silica membrane can be peeled off by large differences of pressure, which might cause leakage of $\mathrm{H}_{2}$ and $\mathrm{CO}_{2}$ from the membrane reactor part. According to the safety regulations, pure hydrogen gas never introduced into the inner tube directly, and hydrogen gas should be diluted with $\mathrm{CO}_{2}$.

\subsubsection{Reaction unit}

For better clarification of the reaction unit, a schematic diagram of membrane reactor is presented in Figure 2. As shown in Figure 2a, the reactor consists of two cylindrical tubes, the inner tube (AB; 
i.d. $1 \mathrm{~cm}$ ) being covered with an outer tube (i.d. $3 \mathrm{~cm}$ ). The outer tube is made of SUS 316 stainless steel; divided in to three chambers R1, R2, and R3. It has to be mentioned that, the inner tube comprises of three sections B1, B2 and B3, each of those are $10 \mathrm{~cm}$ in length. Both B1 and B3 are made of same material (SUS 316) differing from that of $\mathrm{B} 2$, which is made of macroporous $\alpha-\mathrm{Al}_{2} \mathrm{O}_{3}$, where a macroporous $\alpha-\mathrm{Al}_{2} \mathrm{O}_{3}$ membrane is usually used as support layer having no separation capability [13]. The tube B2 connects B1 and B3 on its both sides comprising a total tube length of $30 \mathrm{~cm}$ (inner tube). An enlarged version of the main part of CMFR made up by B2 and R2 is shown in Figure $2 b$.

Figure 2. Modeled diagram of the catalytic membrane flow reactor; (a) Whole reaction unit (with photo) and (b) Reaction zone, where reaction takes place. (c) Cross section of reaction zone.
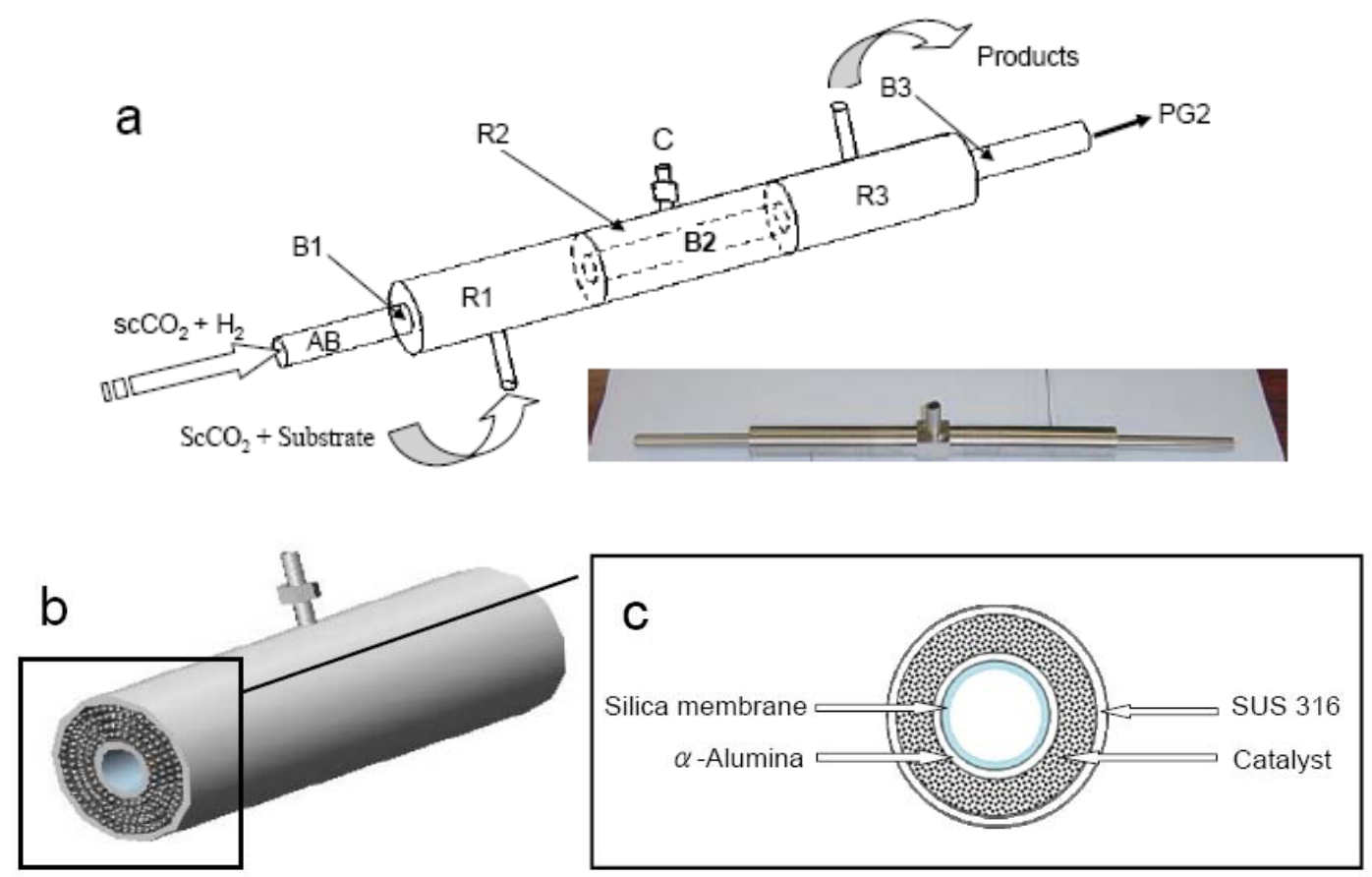

A mesoporous silica membrane was fabricated on the inner wall of the $\alpha-\mathrm{Al}_{2} \mathrm{O}_{3}$ support (tube $\mathrm{B} 2$ ). In the case of the outer tube, two stainless steel nets are connected between R1-R2 and R2-R3. The space between the inner tube (B2) and outer tube (R2) was filled with the catalyst through the port C, and closed securely to prevent any leakage of reactant gases. The pore sizes of the nets are maintained in such way that the catalysts can be retained in the reaction chamber letting the product go out from the system through the outlet attached with chamber R3. Figure 2c shows the cross section of the main part of CMFR (Figure 2b). Figure 3a shows the TEM image of the mesoporous silica membrane that was installed inner wall of the inner tube, and Figure $3 \mathrm{~b}$ shows the TEM image of Pd/MCM-41 catalyst whose pore size is $3.52 \mathrm{~nm}$, surface area is $981 \mathrm{~m}^{2} / \mathrm{g}$, and loaded Pd (nano particle) is $\sim 1 \mathrm{wt} \%$. Figure 4 shows the gas diffusion processes through the membrane. The premixed $\mathrm{H}_{2}$ and $\mathrm{CO}_{2}$ gases are being pumped by a high pressure pump $\mathrm{P} 1$ to the inner tube $\mathrm{B} 2$. The silica membrane is selective to the 
$\mathrm{H}_{2}$ gas and allows diffusion through porous silica membrane toward the catalyst chamber, which is one of the most significant points of this new reactor system. After entering into the catalytic bed $\mathrm{H}_{2}$ activates the metal catalyst active sites of the catalyst and reacts with substrate. The product is then collected through a back pressure regulator (BPR) using a cooled trap. In this newly developed reactor, any $\mathrm{H}_{2}$ selective porous inorganic membrane, such as zeolite membrane, alumina-silicate membrane, silica membrane or composite membrane can be used successfully.

Figure 3. (a) TEM image of the mesoporous silica installed on the inner wall of the inner tube (B2) of membrane reactor; (b) TEM image of Pd/MCM-41 catalyst having pore size $3.52 \mathrm{~nm}$, surface area $981 \mathrm{~m}^{2} / \mathrm{g}$, and $\mathrm{Pd} \sim 1 \mathrm{wt} \%$.
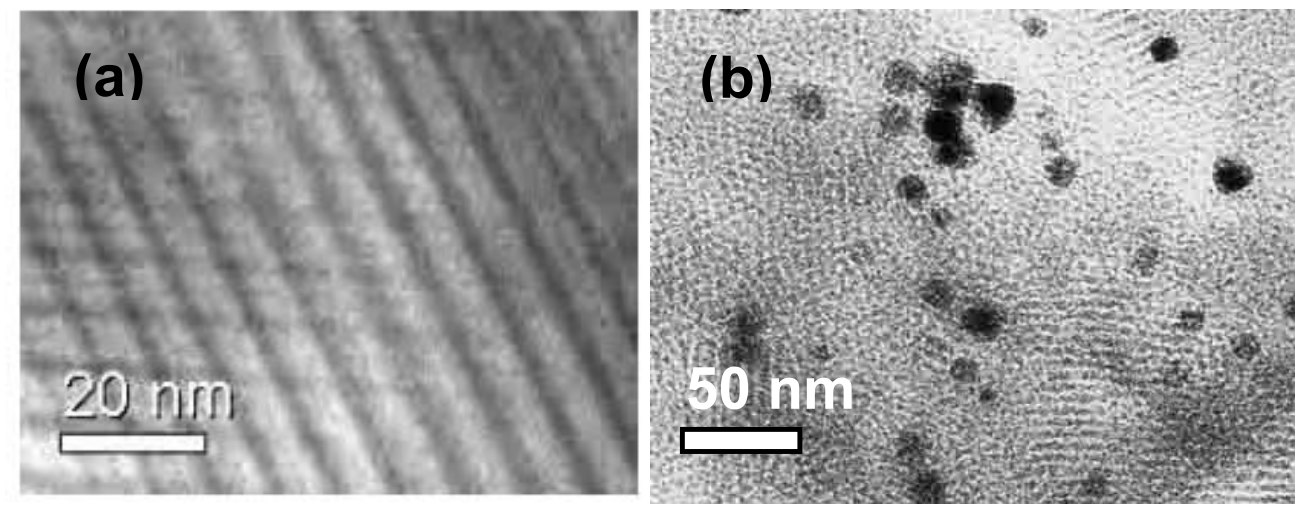

Figure 4. Diagram of hydrogen diffusion process from inner tube to catalytic bed through the membrane.

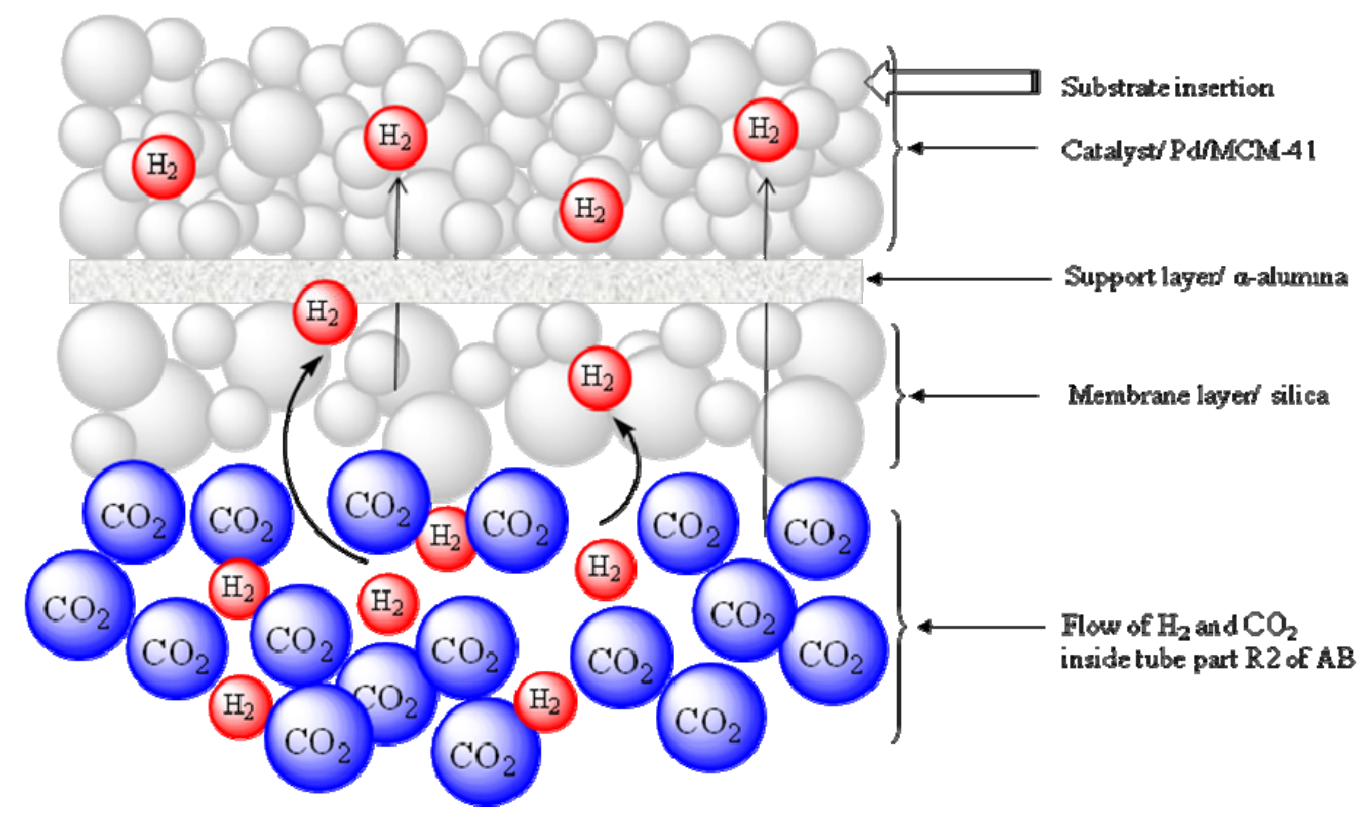




\subsubsection{Preparation of the mesoporous silica membrane on $\alpha-\mathrm{Al}_{2} \mathrm{O}_{3}$ support}

The mesoporous silica membrane has been prepared by a typical hydrothermal method [14]. Briefly, $10 \mathrm{~g}$ of triblock copolymer P123, is dissolved in $175 \mathrm{~g}$ water containing $15 \mathrm{~mL}$ of $\mathrm{HCl}(1 \mathrm{M})$ and the resulting solution is stirred at $35^{\circ} \mathrm{C}$ for $1 \mathrm{~h}$. After that TEOS is added to the above solution and the resulting silica sol solution is stirred again vigorously for $1 \mathrm{~h}$. The mole ratio of the resultant gel is $175 \mathrm{H}_{2} \mathrm{O}: 1: 0 \mathrm{P} 123: 0.017 \mathrm{HCL}: 1$ TEOS. The silica gel is then introduced inside the $\alpha-\mathrm{Al}_{2} \mathrm{O}_{3}$ support. Finally, the membrane is dried for $48 \mathrm{~h}$ at room temperature. To remove the structure directing surfactant, the as-made mesoporous silica membrane is calcined at $450{ }^{\circ} \mathrm{C}$ for $6 \mathrm{~h}$. The resultant membrane is characterized by powder X-ray diffraction pattern (XRD; not shown) and transmission electron microgram (TEM). Figure 3a shows the TEM image of the membrane taken by scrapping some sample from the tube, which exhibits a regular pattern of hexagonal mesoporous structure.

\subsubsection{Catalyst synthesis}

Pd catalyst supported on MCM-41 ( 1 wt \% Pd) has been prepared by a typical hydrothermal method [15]. Pd salt solution is added to CTABr solution containing $\mathrm{NaOH}$. TEOS is added dropwise to the above solution with stirring for $1 \mathrm{~h}$. The resulting gel is then loaded into Teflon-lined stainless-steel autoclave and heated at $100{ }^{\circ} \mathrm{C}$ for $72 \mathrm{~h}$ in static condition. The solid product is recovered by filtration, washed with water and dried at ambient temperature. The occluded organic material is removed by calcined at $550^{\circ} \mathrm{C}$ for $10 \mathrm{~h}$.

\section{Results and Discussion}

\subsection{Test of Catalytic Hydrogenation in the CMFR}

In order to test the performance of the newly developed membrane reactor, we have attempted the selective hydrogenation of cinnamaldehyde (an $\alpha, \beta$ unsaturated aldehyde) in $\mathrm{scCO}_{2}$ as a model reaction (Scheme 1). The reaction was carried out using Pd-MCM-41 ( $\mathrm{Pd} \sim 1 \mathrm{wt} \%$ ) catalyst at $50{ }^{\circ} \mathrm{C}$ in the pressure range of 9-16 $\mathrm{MPa}$ of $\mathrm{CO}_{2}$ and 1-1.5 $\mathrm{MPa} \mathrm{H}_{2}$ with substrate flow rate of ranging from 0.05 to $1.0 \mathrm{~mL} / \mathrm{min}$.

Scheme 1. Hydrogeneration of cinnamaldehyde ( $\alpha, \beta$-unsaturated aldehyde) in $\mathrm{scCO}_{2}$.

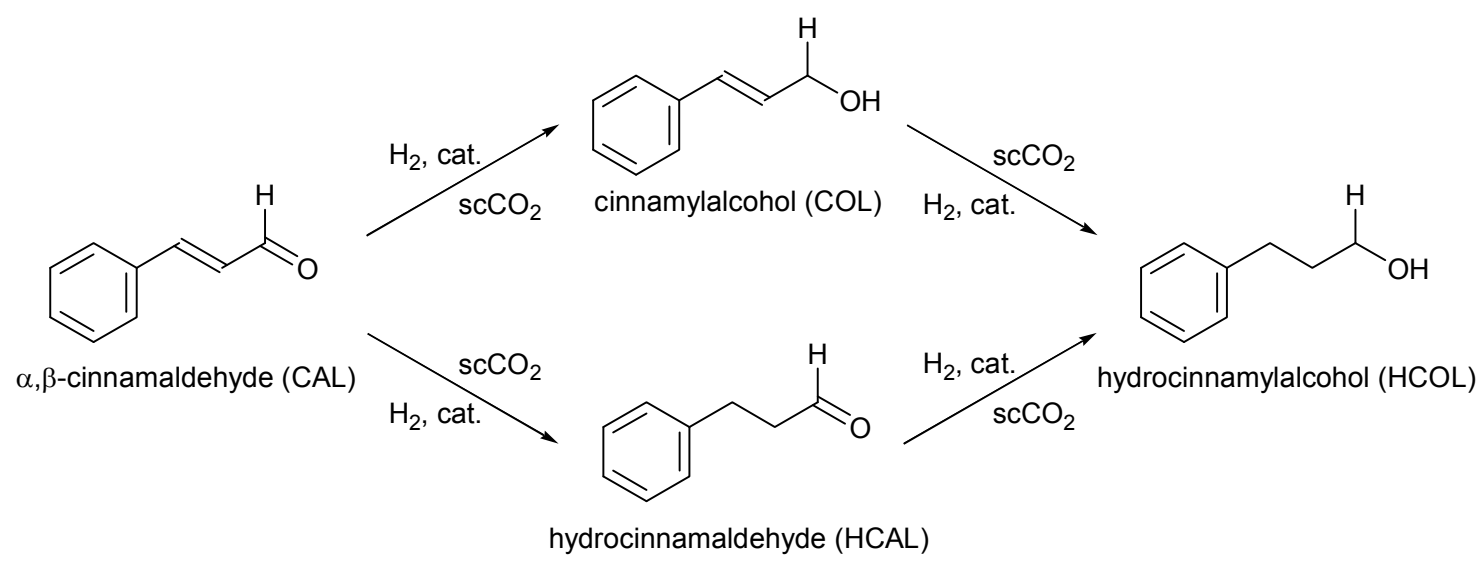




\subsection{Phase Diagram}

Before the reaction, the phase behavior was studied with a high-pressure view cell (cell volume: $10 \mathrm{~mL}$ attached sapphire windows), as it is an important concern for a better understanding of the operation of the catalytic system in $\mathrm{scCO}_{2}$. The solubility of CAL in a mixture of $\mathrm{CO}_{2}$ and $\mathrm{H}_{2}$ is estimated from the phase behavior inspection at $50{ }^{\circ} \mathrm{C}$. From the visual observation, it has been found that at constant $\mathrm{H}_{2}$ pressure of $1 \mathrm{MPa}$, the solubility of CAL increases with increasing $\mathrm{CO}_{2}$ pressure from $6 \mathrm{MPa}$ to $12 \mathrm{MPa}$ and a homogeneous phase is obtained at above $12 \mathrm{MPa}$, and transition phase from gas-liquid two-phase to a supercritical phase (single) at $9 \mathrm{MPa}$ of $\mathrm{CO}_{2}$ was observed (Figure 5).

Figure 5. Phase behavior studies with $\mathrm{CAL}$ at $50{ }^{\circ} \mathrm{C}, 1 \mathrm{MPa} \mathrm{H}_{2}$ and (a) $6 \mathrm{MPa}$ (Total $7 \mathrm{MPa}$ ), (b) $9 \mathrm{MPa}$ (Total $10 \mathrm{MPa}$ ), and (c) $12 \mathrm{MPa}$ (Total $13 \mathrm{MPa}$ ) of $\mathrm{CO}_{2}$ pressure.
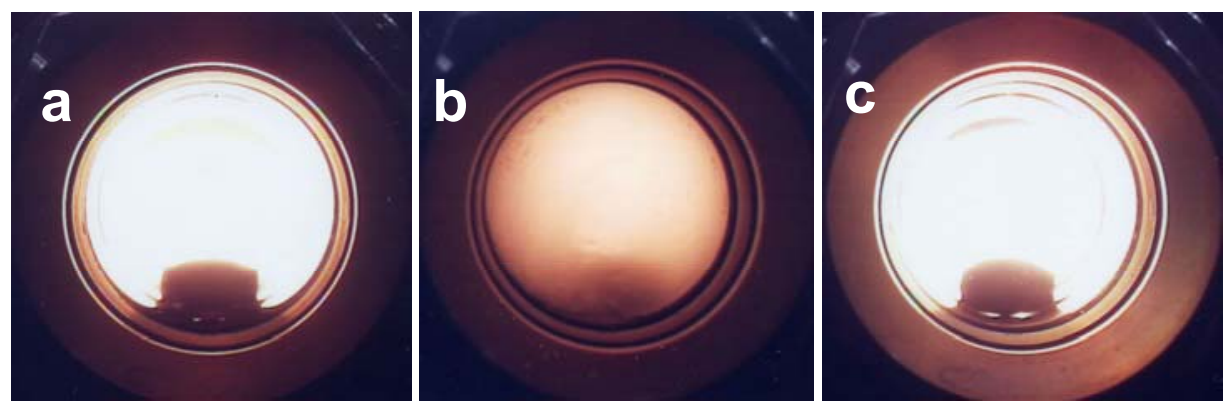

\subsection{Test Reaction}

The probable reaction pathway under the studied reaction conditions is shown in Scheme $1[16,17]$. Table 1 shows the results along with the experimental conditions. According to the primary results, hydrocinnamaldehyde (HCAL) is the major product and the highest selectivity of $100 \%$ (entry 1 ) is obtained at $9 \mathrm{MPa}$ of $\mathrm{CO}_{2}, 1 \mathrm{MPa}$ partial pressure of $\mathrm{H}_{2}$ and the flow rate of substrate is $0.1 \mathrm{~mL} / \mathrm{min}$.

Table 1. Hydrogenation of cinnamaldehyde in $\mathrm{scCO}_{2}$ at $50{ }^{\circ} \mathrm{C}$

\begin{tabular}{|c|c|c|c|c|c|c|c|c|}
\hline \multirow[b]{2}{*}{ Entry } & \multirow{2}{*}{$\begin{array}{c}\mathbf{P}_{\mathbf{H} 2} \\
(\mathbf{M P a})\end{array}$} & \multirow[b]{2}{*}{$\begin{array}{c}\mathbf{P}_{\mathrm{CO} 2} \\
(\mathrm{MPa})\end{array}$} & \multirow{2}{*}{$\begin{array}{c}\text { Flow } \\
\text { CAL } \\
\text { mL/min }\end{array}$} & \multirow[b]{2}{*}{$\begin{array}{l}\text { Time } \\
\text { (min) }\end{array}$} & \multirow{2}{*}{$\begin{array}{c}\text { Conversion } \\
(\%)\end{array}$} & \multicolumn{3}{|c|}{ Selectivity (\%) } \\
\hline & & & & & & $\begin{array}{c}\text { HCAL } \\
(\%)\end{array}$ & $\begin{array}{c}\text { COL } \\
(\%)\end{array}$ & $\begin{array}{c}\text { HCOL } \\
(\%)\end{array}$ \\
\hline 1 & 1 & 9 & 0.1 & 30 & 1.2 & 100 & 0 & 0 \\
\hline 2 & 1 & 9 & 0.1 & 60 & 0.3 & 79 & 0 & 21 \\
\hline 3 & 1 & 9 & 0.05 & 15 & 2.7 & 74 & 0 & 26 \\
\hline 4 & 1 & 12 & 0.05 & 60 & 3.3 & 69 & 0 & 31 \\
\hline 5 & 1 & 12 & 0.05 & 60 & 4.5 & 59 & 0 & 41 \\
\hline 6 & 1.5 & 14 & 0.05 & 60 & 5.3 & 58 & 0 & 40 \\
\hline 7 & 1.5 & 16 & 0.05 & 60 & 5.8 & 65 & 0 & 35 \\
\hline
\end{tabular}

At the higher pressure of $\mathrm{CO}_{2}$ above $12 \mathrm{MPa}$ of supercritical phase, the fully hydrogenated compound, HCOL, was also observed, and HCOL selectivity was showed the maximum at $14 \mathrm{MPa}$ (total pressure: $15 \mathrm{MPa}$ ). Usually, Pd catalysts exhibit high selectivity for the hydrogenation of the $\mathrm{C}=\mathrm{C}$ double bond in $\mathrm{scCO}_{2}[16,17]$. The present study shows that the higher selectivity of HCAL by 
the hydrogenation of $\mathrm{C}=\mathrm{C}$ double bond can be attributed to the diffusion of $\mathrm{H}_{2}$ through the membrane and its reaction with the substrate successfully at around $9 \mathrm{MPa}$ of transition phase. Furthermore, as the flow rate and retention time decrease (Entry 3) the conversion increases, but formation of the saturated compound 3-phenylpropanol (HCOL) was observed. This result indicates that as $\mathrm{H}_{2}$ is readily available on the catalyst surface, HCAL, which was formed previously, is converting to HCOL. Moreover, no reaction has taken place in the absence of membrane on the inner wall of the $\alpha$-alumina support under the same reaction conditions as mentioned in the Table 1. So, it could be concluded that the membrane is functionally active and playing an important role to carry out the hydrogenation reaction of CAL. Our future plans are to extend the use of this type of reactor to other different types of reaction by varying the membrane. Thus, the combination of a suitable membrane along with $\mathrm{scCO}_{2}$ might be one of the key tools to enhance the selectivity of the reaction.

\section{Conclusions}

We developed a high-pressure catalytic membrane reactor for continuous flow reactions in $\mathrm{scCO}_{2}$. The reactor was preliminarily tested with the hydrogenation of cinnamaldehyde. A $100 \%$ selectivity of HCAL from cinnamaldehyde was achieved at $10 \mathrm{MPa}$ of the total pressure $\left(\mathrm{H}_{2}: 1 \mathrm{MPa}, \mathrm{CO}_{2}: 9 \mathrm{MPa}\right.$, $50{ }^{\circ} \mathrm{C}$ ) after $30 \mathrm{~min}$ of reaction time. The use of this type of membrane reactor provides several advantages such as short reaction time, easy product separation from reactant, control and prevention of side reactions, etc. This high-pressure membrane reactor could offer attractive research opportunities, not only to the field of membrane reactors but also in heterogeneous catalysis in $\mathrm{scCO}_{2}$. For future work, we will improve the reactor to scale-up the productivity from laboratory scale to the industrial scale for industrial approaches.

\section{Acknowledgements}

This research was partly supported by the Project of "Development of Microspace and Nanospace Reaction Environment Technology for Functional Materials" of New Energy and Industrial Technology Development Organization (NEDO), Japan and the authors are thankful to the e8 group (www.e8.org) for the postdoctoral scholarship of Nazrul M. Islam on the education for sustainable energy development (ESED) programs.

\section{References and Notes}

1. Johnston, K.P.; Lemert, R.M. Supercritical fluid technology: Theory and application. In Encyclopedia of Chemical Processes and Design; McKetta, J.J., Weismantel, G.E., Eds.; Dekker: New York, NY, USA, 1996.

2. Stephenson, P.; Licence, P.; Ross, S.K.; Poliakoff, M. Continuous catalytic asymmetric hydrogenation in supercritical $\mathrm{CO}_{2}$. Green Chem. 2004, 6, 521-523.

3. Van den Broeke, L.J.P.; Goetheer, E.L.V.; Verkerk, A.W.; Wolf, E.; Deelman, B.-J; Koten, G.V.; Keurentjes, J.T.F. Homogenous reaction in supercritical carbon dioxide using a catalysts immobilized by a microporous silica membrane. Angew. Chem. Int. Ed. 2001, 40, 4473-4474. 
4. Turlan, D.; Urriolabeitia, E.P.; Navarro, R.; Royo, C.; Menendez , M.; Santamaria, J. Separation of Pd complexes from a homogeneous solution using zeolite membranes. Chem. Commun. 2001, 2608-2609.

5. Nair, D.; Scarpello, J.T.; Vankelecom, I.F.J.; Freitas, L.M.; Santos, D.; White, L.S.; Kloetzing, R.J.; Welton, T.; Livingston, A.G. Increased catalytic productivity for nanofiltration-coupled Heck reactions using highly stable catalyst systems. Green Chem. 2002, 4, 319-324.

6. Goetheer, E.L.V.; Verkerk, A.W.; van den Broeke, L.J.P.; de Wolf, E.; van Koten, G.; Keurentjes, J.T.F. Membrane reactor for homogeneous catalysis in supercritical carbon dioxide. J. Catal. 2003, 219, 126-133.

7. Armor, J.N. Catalysis with permselective inorganic membranes. Appl. Catal. 1989, 49, 1-25.

8. Bein. T. Synthesis and applications of molecular sieve layers and membranes. Chem. Mater. 1996, $8,1636-1653$.

9. Katsaros, F.K.; Steriotis, T.A.; Stubos, A.K.; Mitropoulos, A.; Kanellopoulos, N.K.; Tennison, S. High pressure gas permeability of microporous carbon membranes. Microporous Mater. 1997, 8, 171-176.

10. Koros, W.J.; Mahajan, R. Pushing the limits on possibilities for large scale gas separation: which strategies? J. Membr. Sci. 2000, 175, 181-196.

11. Lee, D.; Zhang, L.; Oyama, S.T.; Niu, S.; Saraf, R.F. Synthesis characterization and gas permeation properties of a hydrogen permeable silica membrane supported on porous alumina. J. Membr. Sci. 2004, 231, 117-126.

12. Kainz, S.; Koch, D.; Leitner, W.; Baumann, W. Perfluoralkylsubstituted arylphosphanes as ligands for homogeneous catalysis in supercritical carbon dioxide. Angew. Chem. Int. Ed. 1997, 6, 1628-1630.

13. Dixon, A.G. Recent research in catalytic inorganic membrane reactor. Int. J. Chem. React. Eng. 2003, 1, 1-35.

14. Kang, T.; Oh, S.; Kim, H.; Yi, J. Facile synthesis of mesoporous silica sublayer with hierarchical pore structure on ceramic membrane using anionic polyelectrolyte. Langmuir 2005, 21, 5859-5864.

15. Chatterjee, M.; Iwasaki, T.; Onodera, Y.; Nagase, T. Synthesis of nanosized platinum cluster in cubic mesoporous material via a direct introduction method. Catal. Lett. 1999, 61, 199-202.

16. Chatterjee, M.; Chatterjee, A.; Ikushima, Y. Pd-catalyzed completely selective hydrogenation of conjugated and isolated $\mathrm{C}=\mathrm{C}$ of citral (3,7-dimethyl-2, 6- octadienal) in supercritical carbon dioxide. Green Chem. 2004, 6, 114-118.

17. Burgener, M.; Furrer, R.; Mallat, T.; Baiker, A. Hydrogenation of citral over Pd/alumina: comparison of "supercritical" $\mathrm{CO}_{2}$ and conventional solvents in continuous and batch reactors. Appl. Catal. A: Gen. 2004, 268, 1-8.

(C) 2010 by the authors; licensee Molecular Diversity Preservation International, Basel, Switzerland. This article is an open-access article distributed under the terms and conditions of the Creative Commons Attribution license (http://creativecommons.org/licenses/by/3.0/). 